\title{
Orphan nuclear receptors as regulators of intratumoral androgen biosynthesis in castration-resistant prostate cancer
}

\author{
Jianfu Zhou ${ }^{1,2,3} \cdot$ Yuliang $\mathrm{Wang}^{3} \cdot{\text { Dinglan } \mathrm{Wu}^{4} \cdot \text { Shusheng Wang }}^{1} \cdot$ Zhiqiang Chen $^{1} \cdot$ Songtao Xiang $\mathbb{D}^{1}$ • \\ Franky Leung Chan $\mathbb{1}^{3}$
}

Received: 28 October 2020 / Revised: 18 February 2021 / Accepted: 24 February 2021 / Published online: 9 March 2021

(c) The Author(s), under exclusive licence to Springer Nature Limited 2021. This article is published with open access

\begin{abstract}
Castration-resistant prostate cancer (CRPC) almost invariably occurs after androgen-deprivation therapy (ADT) for the advanced metastatic disease. It is generally believed that among multiple mechanisms and signaling pathways, CRPC is significantly driven by the reactivation of androgen receptor (AR) signaling in ADT-treated patients with castrate levels of androgen, partially at least mediated by the androgen biosynthesis within the tumor, also known as intratumoral or intraprostatic androgen biosynthesis. Steroidogenic enzymes, such as CYP11A1, CYP17A1, HSD3B1, AKR1C3 and SRD5A, are essential to catalyze the conversion of the initial substrate cholesterol into potent androgens that confers the CRPC progression. Accumulating evidences indicate that many steroidogenic enzymes are upregulated in the progression setting; however, little is known about the dysregulation of these enzymes in CRPC. Orphan nuclear receptors (ONRs) are members of the nuclear receptor superfamily, of which endogenous physiological ligands are unknown and which are constitutively active independent of any physiological ligands. Studies have validated that besides AR, ONRs could be the potential therapeutic targets for prostate cancer, particularly the lethal CRPC progression. Early studies reveal that ONRs play crucial roles in the transcriptional regulation of steroidogenic enzyme genes. Notably, we and others show that three distinct ONRs, including liver receptor homolog-1 (LRH-1, NR5A2), steroidogenic factor 1 (SF-1, AD4BP, NR5A1) and estrogen-related receptor $\alpha(E R R \alpha, N R 3 B 1)$, can contribute to the CRPC progression by promotion of the intratumoral androgen synthesis via their direct transcriptional regulation on multiple steroidogenic enzymes. This review presents an overview of the current understanding on the intratumoral androgen biosynthesis in CRPC, with a special focus on the emerging roles of ONRs in this process.
\end{abstract}

\section{Introduction}

These authors contributed equally: Jianfu Zhou, Yuliang Wang

Songtao Xiang

tonyxst@gzucm.edu.cn

$\triangle$ Franky Leung Chan

franky-chan@cuhk.edu.hk

1 Department of Urology, The Second Affiliated Hospital of Guangzhou University of Chinese Medicine, Guangzhou, China

2 The Second Clinical College, Guangzhou University of Chinese Medicine, Guangzhou, China

3 School of Biomedical Sciences, Faculty of Medicine, The Chinese University of Hong Kong, Hong Kong, China

4 Shenzhen Key Laboratory of Viral Oncology, The Clinical Innovation \& Research Center, Shenzhen Hospital, Southern Medical University, Shenzhen, China
Prostate cancer is the most frequently diagnosed malignancy among males in majority of economically developed countries, and is the second most common cancer in men worldwide [1, 2]. The growth and survival of prostate cancer cells are sustained by androgens through the activation of androgen receptor (AR) and its mediated signalings. Thus, androgens, particularly testosterone (T) and dihydrotestosterone (DHT), which serve as the major endogenous ligands of AR, are the key drivers for both the initiation and progression of prostate cancer. Androgendeprivation therapy (ADT) or hormone therapy, with a primary aim of depletion of gonadal $\mathrm{T}$ and achieved by either medical or surgical castration with or without combination of antiandrogen, has been conventionally used as the standard upfront treatment for locally advanced and metastatic prostate cancer. Unfortunately, the response is 
usually transient and almost all patients inevitably relapse with progression to the aggressive and fatal castrationresistant prostate cancer (CRPC) [3]. Although not fully understood, multiple and interconnected mechanisms may be involved in castration resistance [4], including intratumoral androgen biosynthesis, AR pathway hypersensitivity due to AR gene amplification, AR activation (often mediated by AR mutations) by noncognate ligands such as corticosteroids or even antiandrogens, increased AR transcription activity mediated by oncogenic growth factoractivated signal pathways, expression of variant AR isoforms (e.g., AR-V7) that are ligand-independent, activation of alternative AR-independent or AR-bypass pathways, and selection of pre-existing prostate cancer stem cells [5, 6]. Among these, the intratumoral or intraprostatic androgen biosynthesis and persistent AR signaling are regarded as the key factors responsible for the progression of CRPC [7]. In this review, we update the current understanding of intratumoral androgen biosynthesis in CRPC, with a particular focus on the emerging roles of ligand-independent orphan nuclear receptors (ONRs) involved in this process.

\section{Evidences of intratumoral androgen biosynthesis as a key driver in CRPC}

It has been well-characterized that DHT is much more potent than $\mathrm{T}$ to activate $\mathrm{AR}$, and is the main androgen bound to $\mathrm{AR}$ in the nuclei of prostatic cells. Although the presence of intratumoral DHT was first noted over 30 years ago in patients relapsed from orchiectomy or estrogen therapy [8], the most supportive evidence that intratumoral androgen biosynthesis acting as a key driving force in CRPC progression is the survival benefit conferred by the recent clinical use of the key steroidogenic enzyme CYP17A1 inhibitor abiraterone acetate as well as the potent AR antagonist enzalutamide [9-12]. Early study in men with CRPC and intact prostates reported that intraprostatic DHT levels in a small subset of patients were increased relative to those men immediately after castration, although these findings were not interpreted as a supportive evidence for the increased androgen biosynthesis within tumors [8]. By radioimmunoassay or more sensitive mass spectrometry methods, both T and DHT are detected in recurrent prostate cancer tissues [13, 14]. Further analysis reveals that higher levels of T and DHT are detected in primary prostate cancers as compared with paired benign prostate tissues; and levels of $\mathrm{T}$ and DHT as measured in the castration-resistant metastases are much higher than those in the non-prostatic control tissues [15]. These results also indicate that residual $\mathrm{T}$ levels of $0.2-2.94 \mathrm{ng} / \mathrm{g}$ and DHT levels of $0.36-2.19 \mathrm{ng} / \mathrm{g}$, as measured in clinical tissues from CRPC patients, are sufficient to activate AR, stimulate AR-regulated genes and enable tumor cell growth and survival [13-15]. Therefore, understanding the source and regulation of androgen biosynthesis is critical to the development of novel effective therapies for better management of CRPC.

\section{Pathways and steroidogenic enzymes mediating androgen biosynthesis in CRPC}

Evidences from the past decade indicate that prostate cancer tissues, especially from CRPC patients, express a spectrum of steroidogenic enzymes responsible for additional catalyzing steps for androgen biosynthesis beyond the canonical physiological conversion of T to DHT [16]. It is currently recognized that up to three potential synthetic pathways exist that might lead to the increased levels of androgen biosynthesis within the tumor in CRPC [17-19]. The frontdoor or classical pathway, which involves the canonical physiological production of $\mathrm{T}$ within the testis de novo from cholesterol or converted from circulating adrenal androgen precursors, is characterized by the necessity of $\mathrm{T}$ as an essential precursor that generates DHT. On the other hand, the primary and secondary backdoor pathways utilize distinct intermediate substrates (progesterone $\rightarrow \rightarrow$ androstanediol $\rightarrow$ DHT or DHEA $\rightarrow \rightarrow 5 \alpha$-Adione $\rightarrow$ DHT) and steroidogenic enzymes to synthesize DHT bypassing $\mathrm{T}$ as the intermediate. A general outline of the front-door and backdoor steroidogenic pathways is illustrated in Fig. 1.

Accumulating evidences show that CRPC tissues as well as xenograft models of CRPC exhibit upregulated expressions of multiple key steroidogenic enzymes responsible for the androgen biosynthesis. In patients with CRPC, dehydroepiandrosterone (DHEA) of adrenal origin and its sulfated derivative (DHEA-S) are implicated as the predominant precursors of $\mathrm{T}$ [20]. Compared with primary prostate tumors, castration-resistant metastases displayed alterations in steroidogenic enzyme genes, including upregulated expression of $C Y P 17 A 1, H S D 3 B 1$, and $H S D 17 B 3$ and down-regulated expression of SRD5A2 [15]. Of note, the reduced expression of SRD5A2 in CRPC is consistent with previous observation that a marked reversal in the ratio of $\mathrm{T}$ to DHT exists in the CRPC tissue as compared to the primary prostate tissues $[13,15]$. Indeed, although DHT is more potent than $\mathrm{T}$ in activating $\mathrm{AR}$, previous kinetic experiments have revealed that $\mathrm{T}$ at high concentrations interacts with AR similarly to DHT [21], and 1.6-fold to 1.9-fold increases in T as compared with DHT are sufficient to achieve comparable prostate regrowth [22]. One study conducted primarily in LNCaP-CRPC xenograft model indicates that expressions of the enzymes required for de novo androgen biosynthesis, including CYP11A1, CYP17A1 and AKR1C3, are increased in castrationresistant sublines. Moreover, we and others show that 


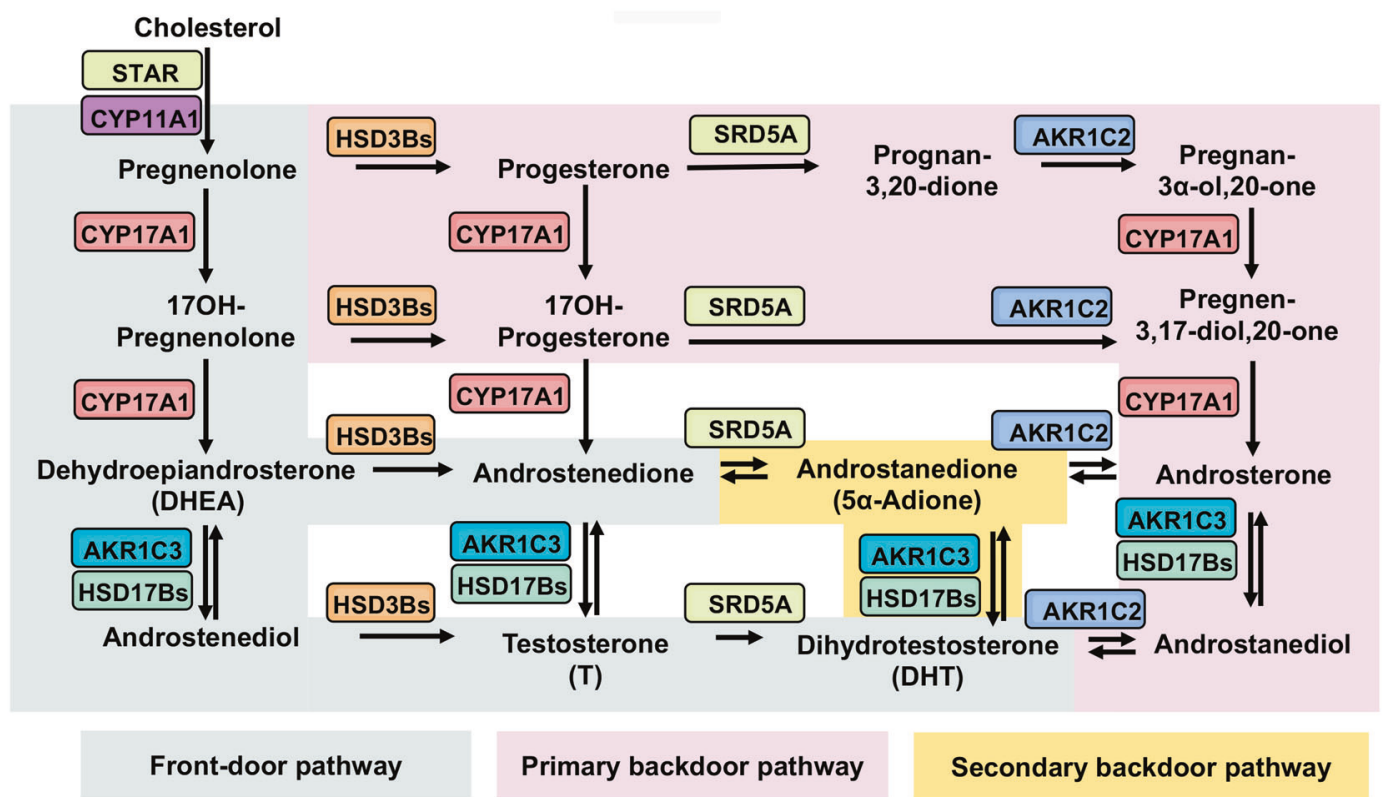

Fig. 1 Recognized pathways of androgen biosynthesis in prostate cancer. Three potential pathways currently exist and function in CRPC that may confer increased levels of androgen biosynthesis within the tumor through the sequential actions of steroidogenic enzymes that are normally active in the testes and adrenal glands. Cholesterol is converted to pregnenolone by the action of STAR and CYP11A1. In the front-door (canonical or classical) pathway (greyish green), characterized by the necessity of testosterone ( $\mathrm{T}$ ) as an essential precursor that generate DHT, pregnenolone is converted to dehydroepiandrosterone (DHEA) by the sequential hydroxylase and lyase activity of CYP17A1. DHEA (from intrinsic or adrenal) is then acted on by HSD3B to yield androstenedione or by HSD17B3 (or AKR1C3) to yield androstenediol, which are subsequently converted to $\mathrm{T}$, followed by its $5 \alpha$-reduction to dihydrotestosterone (DHT) by $5 \alpha$-reductases (SRD5As). On the other hand, the backdoor pathways refer to use of distinct substrates and enzymatic reactions to synthesize

several major steroidogenic enzyme genes involved in androgen biosynthesis (such as steroidogenic acute regulatory gene STAR, CYP11A1, HSD3B2, CYP17A1 and $A K R 1 C 3)$ exhibits upregulated expressions in castrationrelapse $\mathrm{VCaP}$ xenograft model (VCaP-CRPC), and the expressions of $C Y P 17 A 1$ and $A K R I C 3$ are further increased upon treatment with CYP17A1 inhibitor abiraterone $[16,23,24]$. The use of ex vivo radiotracing assays coupled to HPLC/MS detection demonstrates that CRPC tumors are capable of de novo conversion of $\left[{ }^{14} \mathrm{C}\right]$-acetic acid to DHT and uptake of $\left[{ }^{3} \mathrm{H}\right]$-progesterone to steroid precursors of DHT, suggesting that de novo androgen biosynthesis may be a driving force leading to CRPC progression following castration [25]. Another study shows that CYP17Al and $H S D 3 B 1$ mRNA levels are extremely low in locally recurrent CRPC, whereas enzymes that convert androstenedione to T (AKR1C3) and T to DHT (SRD5A1) are abundantly expressed. These results implicate that the enhanced production of adrenal androgens and intratumoral de novo androgen biosynthesis in a subset of CRPC tumors may
DHT bypassing $\mathrm{T}$ as intermediate. In the primary backdoor pathway (pink), the progesterone intermediates are $5 \alpha$ - and $3 \alpha$-reduced by SRD5As and AKR1C2 before the lyase activity of CYP17A1, forming the androsterone and then to androstanediol by HSD17Bs (or AKR1C3) to generate DHT. In the secondary backdoor (5 $\alpha$-Adione) pathway (yellow), androstenedione as produced in the classical pathway is converted to $5 \alpha$-androstenedione ( $5 \alpha$-Adione) by SRD5As instead of conversion to T, and then to DHT by HSD17Bs (or AKR1C3). The necessary steroidogenic enzymes (gene names) catalyzing different steps of androgen biosynthesis are colour-coded across the three pathways. (STAR $=$ steroidogenic acute regulatory protein; CYP11A1 = cholesterol side-chain cleavage enzyme; CYP17A1 = steroid $17 \alpha$-monooxygenase; AKR1C3 = aldo-keto reductase $1 \mathrm{C} 3$; HSD17Bs = 17B-hydroxysteroid dehydrogenases; HSD3Bs = $3 \beta$-hydroxysteroid dehydrogenases; SRD5As = steroid 5 $\alpha$-reductase; AKR1C2 = aldo-keto reductase 1C2.).

require additional suppression of intratumoral AKR1C3 or SRD5A1 activity in order to reduce the conversion of adrenal steroid precursors to the active T and/or DHT and consequently AR pathway activation [26]. Furthermore, a gain-of-function mutation of $H S D 3 B 1$ [3ßHSD1(367T)], a key enzyme regulating the conversion of DHEA via the $5 \alpha$ androstanedione ( $5 \alpha$-dione) pathway to DHT, is detected in CRPC, and the mutant does not affect the catalytic activity but renders the enzyme resistant to ubiquitination and degradation, hence leading to increased DHT level and resulting in AR reactivation [27]. Together, CRPC tumors are characterized by a number of alterations in steroidogenic enzyme gene expression that are consistent with either mediating conversion of adrenal androgen precursors to DHT, or promoting de novo biosynthesis of androgens from cholesterol precursors. Current treatments for CRPC with specific steroidogenic enzyme inhibitors, such as the CYP17A1 inhibitor abiraterone acetate, are insufficient to stop the progression to the lethal form of the metastatic disease [16]. Thus, targeting the upstream factors involved 
in the regulation of expression of steroidogenic enzymes and exploration of the mechanisms via which intratumoral androgen biosynthesis is initiated and maintained represent an attractive and potential novel strategy for the management of CRPC. Indeed, many early studies have validated that transcriptional regulation of human steroidogenic enzyme genes is responsible for the control of steroid hormone biosynthesis in maintaining various physiological processes [28, 29].

\section{Involvement and pathogenesis of orphan nuclear receptors in CRPC}

Orphan nuclear receptors (ONRs) are members of the nuclear receptor (NR) superfamily, and are so named either because their endogenous physiological ligands are unknown or they are constitutively active independent of any physiological ligands [30]. The common structure of ONRs contains four typical functional domains: (1) Nterminal activation domain [or transcriptional activation function-1 site (AF-1)], (2) DNA-binding domain (DBD), (3) hinge region, (4) ligand-binding domain (LBD) and Cterminal activation domain (AF-2) that interacts with coregulators. ONRs share two highly conserved domain structures, DBD and LBD, with other members of NRs. The DBD in NRs is characterized by two cysteine-rich zinc finger motifs, which are required for DNA binding and dimerization of NRs. The LBD contains sites for coactivator and co-repressor interactions, and mediates nuclear localization $[31,32]$. In recent decades, ONRs have been actively characterized in their important regulatory roles involved in numerous key cellular processes and diseases, including cancer and also exploited as potential therapeutic targets for diseases mainly because of the presence of the "druggable" LBD [33, 34].

We have previously reviewed the emerging roles of ONRs in the development of prostate cancer. In particular, some ONR members (including ROR $\gamma$, TR2, TR4, COUPTFII, ERR $\alpha$, DAX-1 and SHP) exhibit multiple cross-talks with AR signaling in both normal and malignant prostatic cells, indicating their intricate interplay in prostate cancer progression [35]. We also surveyed the expression profiles of the entire NR superfamily in 3D-cultured prostate cancer stem- or progenitor-like cells (PCSCs) and castrationrelapse xenografts (VCaP-CRPC), and identified some ONRs (including ROR $\beta$, TLX, COUP-TFII, NURR1 and LRH-1) that show significant common up-regulation in 3Dcultured PCSC-enriched prostatospheroids and CRPC xenografts [24]. Over the years, a number of studies have gained significant advancement and understanding on the roles of ONRs (including ROR $\gamma$ [36], TR4 [37], TLX [38], ERR $\alpha$ [39, 40], SF-1 [41], LRH-1 [23], GCNF [42]) in
CRPC progression. Their characterized roles in CRPC are summarized in Table 1.

\section{Orphan nuclear receptors-mediated intratumoral androgen biosynthesis in CRPC}

Multiple nuclear transcription factors, including ONRs, are found to participate in the transcriptional regulation of steroidogenic enzyme genes expressed in endocrine tissues [43]. Recent studies from us and other group show that the ONRs can contribute to the castration-resistant growth of prostate cancer through their promotion of intratumoral androgen biosynthesis via front-door and/or backdoor pathways by their transcriptional regulation of multiple key steroidogenic enzyme genes [23, 40, 41].

Liver receptor homolog-1 (LRH-1, Ftz-F1, NR5A2), first cloned from a mouse liver cDNA library, belongs to the NR5A subfamily of NR superfamily. Although classified as an ONR, crystallographic studies show that some phospholipids can bind to LRH-1 and modulate its interplay with co-regulators and thus its transactivation [44]. LRH-1 is expressed at moderate to high levels in fetal and adult organs of endodermal origin (liver and intestines), steroidogenic organs (adrenal gland), gonads as well as adipose tissue, and exerts critical roles in the development and differentiation of endodermal organs and gonads, bile acid homeostasis, cholesterol metabolism, and reproduction [45]. LRH-1 has also been implicated in the tumorigenesis of multiple cancers, including breast cancer [46], pancreatic cancer [47], colon cancer [48], liver cancer [49], as well as ovarian epithelial and granulosa cell tumors [50]. Intriguingly, LRH-1 is identified as a critical regulator of steroidogenesis via it direct transcriptional regulation of multiple steroidogenic enzyme genes (e.g., STAR, CYP11A1, HSD3B2, CYP17A1 and CYP19A1) in different steroidogenic organs (adrenal, testis and ovary) and nonsteroidogenic tissues (adipose tissue) [45, 51, 52]. More importantly, LRH-1 can promote breast carcinogenesis by increasing the local estrogen production in adipose stroma surrounding breast carcinomas via its transactivation of the aromatase gene (CYP19A1) [53], suggesting indirectly that LRH-1 may play a positive role in the development of prostate cancer that is also influenced by the microenvironment containing sex steroids. Our recent study shows that LRH-1 displays an increased expression pattern in clinical CRPC tissues, CRPC xenograft models, and also abiraterone-treated CRPC tumors, and its overexpression can promote both in vitro androgen deprivation-resistant and in vivo castration-resistant growth capacities in ARpositive prostate cancer cells via its direct transactivation of multiple key steroidogenic enzyme genes (including STAR, CYP11A1, HSD3B2, CYP17A1) and enhanced intratumoral 


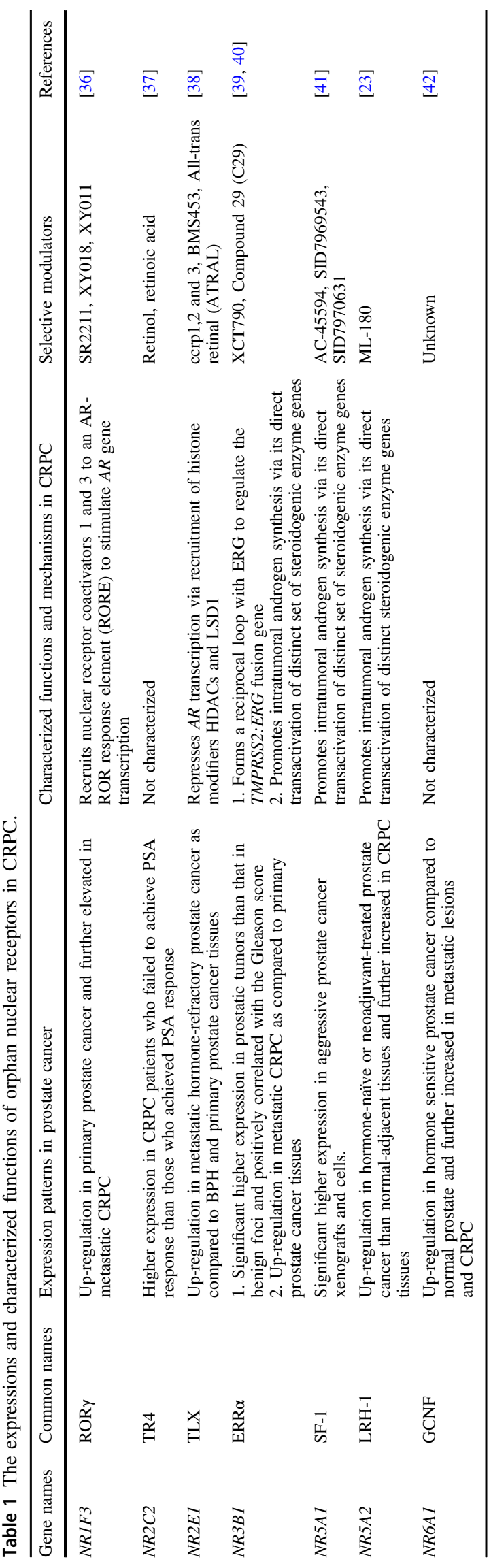

de novo production of androgens ( $\mathrm{T}$ and DHT) in a CYP17A1-dependent manner. Notably, the resistance of prostate cancer cells to androgen-deprivation can be attenuated either by RNAi-mediated knockdown of LRH-1 expression, or by pharmacological suppression of LRH-1 activity with a LRH-1-specific inverse agonist ML-180 [23], suggesting that targeting LRH-1 could be a valuable therapeutic strategy approach for CRPC management.

Steroidogenic factor 1 (SF-1, AD4BP, NR5A1), another orphan member of NR5A subfamily, exhibits a high homology in structure with LRH-1; and functionally these two ONRs often bind to the same or highly similar response elements in their target genes [54]. As its name implies, SF1 is a critical driving factor of steroidogenesis and functions of normal endocrine tissues, and acts as a key transcription factor to regulate the expression of genes responsible for cholesterol metabolism and conversion of steroid hormones $[55,56]$. Previous studies reveal that SF-1 performs similar actions as LRH-1 in rat granulosa cell steroidogenesis [57], and its expression is associated with the aberrant cell growth in adrenocortical and ovarian cancers [58, 59]. Another study shows that SF-1 is essential for the FSH and cAMP signaling cascades to regulate aromatase gene (CYP19A1) and its interaction with $\beta$-catenin is responsible for estrogen production in ovarian granulosa cells [60]. More recently, Lewis et al. report that SF-1 can promote the aggressive growth of CRPC by stimulating steroid biosynthesis and cancer cell proliferation [41]. Their results show that SF-1 expression is absent in benign prostatic cells but present in aggressive prostate cancer cell lines. The presence of SF-1 affects progesterone production and induces the expression of certain steroidogenic enzyme genes, including CYP17Al, HSD3B1, HSD17B3, and CYP19A1. Moreover, SF-1 is sufficient and necessary to promote prostate cancer cell growth and proliferation and also mediate the growth of BCaPT10 prostate cell xenografts within a steroid-depleted environment [41]. Strikingly, the first synthetic SF-1 inverse agonist (AC-45594) is identified through Receptor Selection and Amplification Technology, and it is characterized to potently inhibit SF-1 activity and lead to the downregulation of some key SF-1 target genes, including enzymes critical to steroid biosynthesis [61]. In the same year, through a rational high-throughput screening approach, two analogous isoquinolinones SID7969543 and SID7970631 are identified by another research group, as potent, selective and cell-penetrant inhibitors of SF-1 [62]. These studies implicate that targeting SF-1 may represent a potential therapeutic strategy for patients with CRPC.

Estrogen-related receptor $\alpha(E R R \alpha, \mathrm{NR} 3 \mathrm{~B} 1, E S R R A)$ is an orphan member of the NR3B subfamily and is named due to its high homology with estrogen receptor $\alpha$ (ER $\alpha$, ESR1). Studies in past decades indicate that ERR $\alpha$, together with its coactivators PGC-1s ( $\alpha$ or $\beta$ ), is the master 
transcriptional regulator in multiple bioenergetics pathways and mitochondrial functions, including glucose metabolism, mitochondrial oxidative metabolism and biogenesis [63]. Previously, we and others show that ERR $\alpha$ displays an upregulation pattern in advanced prostate cancer, and is closely linked to its poor clinical and pathological outcomes [39, 64, 65]. Functional and mechanistic studies indicate that ERR $\alpha$ can promote the hypoxic growth adaptation of prostate cancer cells via its stabilization and augmentation of HIF-1 signaling [66], and also can form a reciprocal regulatory loop with an oncogenic transcription factor ERG on the regulation of TMPRSS2:ERG fusion gene and thus to promote the malignant growth of prostate cancer [39]. Interestingly, Seely et al. demonstrate that ERR $\alpha$ can promote the production of adrenal steroids by regulating SULT2A1 that catalyzes the sulfonation of DHEA to more stable DHEA sulfate (DHEA-S) [67]. Moreover, ERR $\alpha$ is characterized to increase the local estrogen production by up-regulating aromatase (CYP19A1) expression in response to prostaglandin E2 in prostate stromal cells [68]. These findings suggest that ERR $\alpha$ can modulate the intracellular steroidogenic capacity, which prompts us to determine the functional roles of ERR $\alpha$ in intratumoral androgen biosynthesis in prostate cancer. As expected, our recent study reveal that ERR $\alpha$, which exhibits an up-regulation expression pattern in metastatic CRPC tissues and also the castration-relapse VCaP-CRPC xenograft model, can function to promote the castration-resistant growth of prostate cancer by enhancing the intratumoral androgen biosynthesis and thus activation of AR signaling via a mechanism of direct transactivation of two key androgen biosynthesis enzyme genes CYPIIAI and AKRIC3 [40]. In addition to enhancing de novo androgen synthesis from cholesterol via its regulation of CYP11A1, ERR $\alpha$ can also increase intratumoral DHT biosynthesis via the secondary backdoor pathway (DHEA $\rightarrow \rightarrow 5 \alpha$-Adione $\rightarrow$ DHT) by directly targeting the AKRIC3. More importantly, inhibition of ERR $\alpha$ activity by its inverse agonist XCT790 or Compound 29 (C29), not only can attenuate the intratumoral androgen production and suppress AR signaling in prostate cancer cells, but also significantly prevent the castration-relapsed tumor growth accompanied with a decrease of intratumoral DHT production and reduced expression of AKR1C3, suggesting that targeting ERR $\alpha$ could be a potential ADT strategy for CRPC management [40].

Together, these findings represent a novel paradigm of regulation of intratumoral androgen biosynthesis in CRPC, in which prostate tumor cells may switch over to alternative pathways of androgen production and buffer themselves from the insufficiency of systemic androgens following ADT via different ONR-mediated transcriptional regulation of steroidogenic enzymatic machinery. It is worth noting that the three ONRs can target both common (e.g.,
CYP17A1 by LRH-1 and SF-1, CYP11Al by LRH-1 and ERR $\alpha$ ) and specific steroidogenic enzyme genes, and therefore be involved in distinct pathways of androgen biosynthesis in prostate cancer, in which ERR $\alpha$ and SF-1 participate in both front-door and backdoor pathways of DHT biosynthesis, whereas LRH-1 is responsible for the similar pathways except the secondary backdoor pathway. These results indicate that different ONRs may perform either differential or synergistic roles in the biosynthesis of DHT via their regulation of different or common steroidogenic enzyme genes involved in the intratumoral androgen biosynthesis in CRPC. Therefore, targeting the druggable ONRs could be a valuable therapeutic strategy approach for CRPC treatment. The working model of ERR $\alpha$, LRH- 1 and SF-1 in intratumoral androgen biosynthesis in prostate cancer cells is illustrated in Fig. 2.

In addition to the three reported ONRs with implicated functions in intratumoral androgen biosynthesis in prostate cancer, several other orphan members of NR superfamily have been characterized to be involved in steroidogenesis in certain non-prostatic organs or tissues, suggesting that these ONRs may also be the potential regulators in intraprostatic or intratumoral androgen biosynthesis in prostate cancer and yet to be further characterized [69]. COUP-TFII (NR2F2), an ONR of the highly conserved NR2F subfamily, displays an increased expression pattern in advanced prostate cancer, and its expression is positively correlated with prostate tumor recurrence and progression [70-72]. One study performed in the mouse Leydig cells reveals that COUP-TFII can promote androgen production by directly transactivating the expression of STAR that is responsible for the cholesterol transport within the mitochondrial matrix, the first and the key step for steroidogenesis. In addition, COUP-TFII can cooperate with SF-1 on the activation of STAR gene promoter, due to the overlaps of binding elements between COUP-TFII and SF-1 [73]. However, some opposite observation was noted, in which the COUP-TF family members (COUP-TFI/NR2F1 and COUP-TFII/ $N R 2 F 2$ ) are proposed as negative regulators of steroidogenesis in bovine glomerulosa cells [74]. Therefore, the regulatory roles of COUP-TFII in steroidogenesis may be likely tissue- or species-type dependent. Similarly, Nurr77 (NR4A1), an orphan member of the NR4A subfamily, which is highly expressed in advanced prostate cancer and characterized to promote prostate cancer invasion following ADT [75], can control the STAR transcription in mouse Leydig cells in either SF-1-dependent or -independent manner [76, 77]. Lastly, two atypical members of the NR superfamily without the classical zinc-finger containing DBD, DAX-1 (NROB1) and SHP (NROB2), also play regulatory roles in steroidogenesis, generally acting as the coregulators of SF-1 or LRH-1. DAX-1 is frequently regarded as a negative regulator of steroidogenesis, where it can 


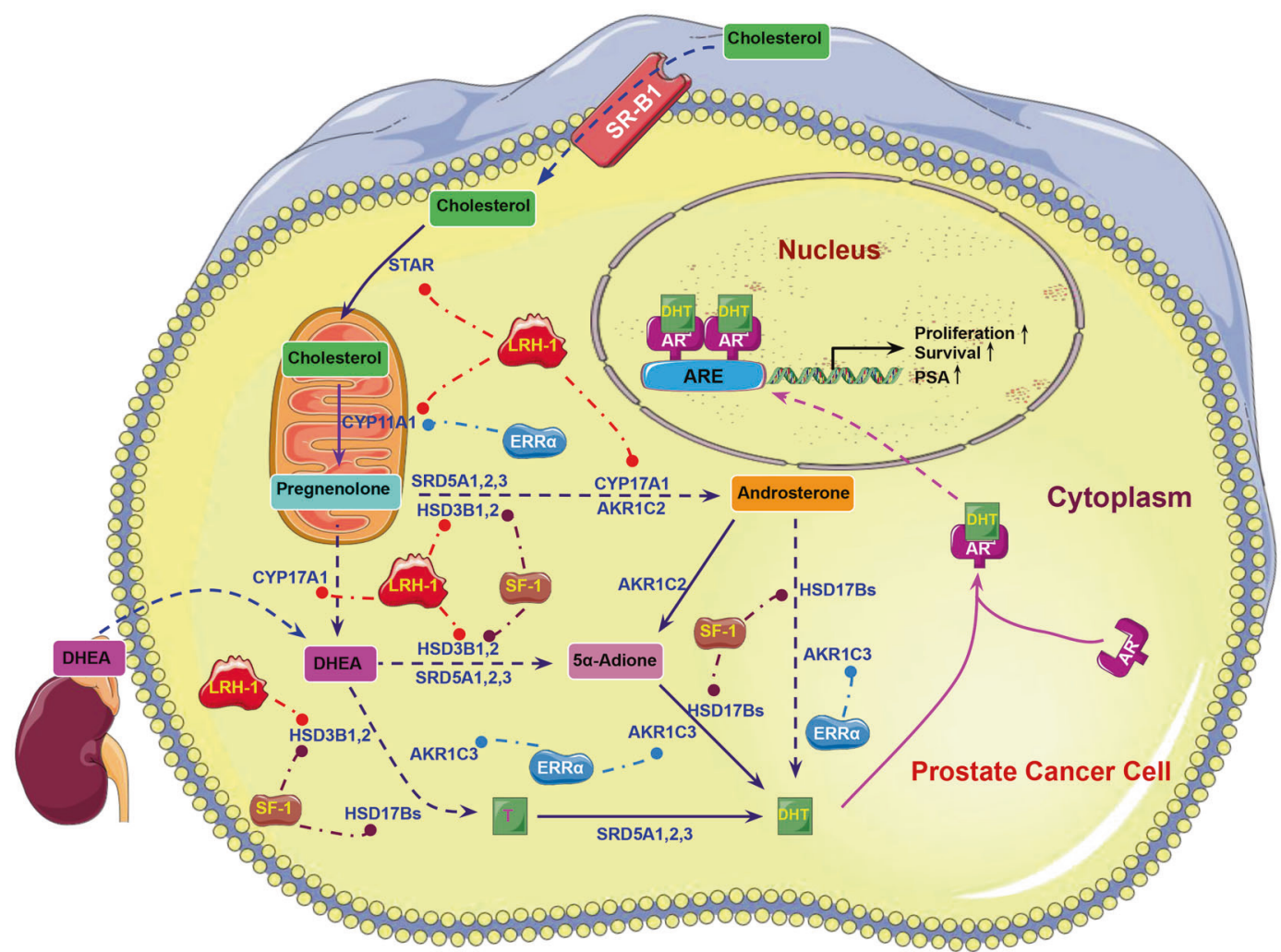

Fig. 2 Schematic diagram illustrates the specific roles of ERR $\alpha$, LRH-1, and SF-1 in the regulation of key enzymatic genes involved in intratumoral androgen biosynthesis in prostate cancer cells. Multiple key enzymatic genes involved in distinct pathways of androgen biosynthesis can be transcriptionally

repress the LRH-1-mediated transcription of HSD3B2 (3ßHSD2) in ovarian granulosa cells [78], and also inhibit SF-1-mediated transcription of genes involved in androgen biosynthesis (STAR, CYP11A1, and CYP17A1) in adrenal cells $[79,80]$. In regard to SHP, previous studies show that deficiency of SHP results in higher circulating $\mathrm{T}$ levels in SHP-knockout mice due to enhanced expression of steroidogenic genes STAR and CYP11Al, which is mediated by LRH-1 [81]; and besides, SHP can also repress the expression of CYP17Al by preventing the binding of LRH1 to its promoter in liver cells [82].

\section{Concluding remarks and future perspectives}

Intratumoural androgen biosynthesis represents a key mechanism driving the castration-resistant progression in advanced prostate cancer. Some key steroidogenic enzymes, which are upregulated in CRPC and hence supporting the relapse growth of CRPC, have become the emerging therapeutic targets for CRPC with a therapeutic purpose to reduce the intraprostatic androgen levels. Current treatment for metastatic and therapy-resistant CRPC with the activated by ERR $\alpha, \mathrm{LRH}-1$, and SF-1; and their transactivations contribute to the increase of intratumoral androgen concentration in prostate cancer cells, resulting in activation of AR signaling and thus fueling the castration-resistant growth of prostate cancer cells.

CYP17A1 inhibitor, abiraterone acetate, is initially effective but still cannot stop the lethal progression of the disease. Thus, targeting the upstream factors involved in the regulation of steroidogenic enzymes and exploration of the mechanisms by which intratumoral androgen biosynthesis is initiated and maintained may represent a potential novel strategy for the management of CRPC. Over the years, studies on ONRs have gained sufficient insights to our current understanding on their roles in prostate cancer advancement, particularly CRPC. Given their important roles in the transcriptional regulation of steroidogenesis as well as CRPC, studies shown by us and others reveal that three distinct ONRs, including ERR $\alpha$, LRH-1 and SF-1, can contribute to the CRPC progression by promoting the intratumoral androgen biosynthesis through their positive and differential transcriptional regulation of multiple critical steroidogenic enzyme genes involved in both the front-door and backdoor pathways of androgen biosynthesis. Although the endogenous ligands for ONRs have not yet been identified, more and more synthetic compounds working as agonists, inverse agonists or antagonists for ONRs have been developed recently (refer to Table 1). It is worthy of further studies to identify or develop novel ONRs 
modulators (natural or synthetic compounds) as the potential therapeutic agents for better management of CRPC.

Acknowledgements The work described in this article was partially supported by the National Natural Science Foundation of China (No. 81774067, 81802575, 82072830, 81872283), Medical Science and Technology Research Fund of Guangdong Province (No. A2020239), Specific Research Fund for TCM Science and Technology of Guangdong Provincial Hospital of Chinese Medicine (No. YN2016MJ03), Guangdong-Hong Kong collaborative innovation projects from the Department of Science and Technology of Guangdong Province (No. 2017A050506042) and Guangdong Provincial Hospital of Chinese Medicine (No. YN2018HK02); and also by grants from the General Research Fund (project numbers: 461009, 2140789, 14100914, 14107116, 14110918), Research Grants Council of Hong Kong; a grant from the Health and Medical Research Fund (project number: 02130066), Food and Health Bureau of Hong Kong (to FLC). JZ was awarded by the Eternal Flame Scholar Programme of Guangzhou University of Chinese Medicine.

Author contributions JZ and YW performed the literature search, data analysis, and drafted the paper. YW coordinated on illustrations as well as linguistics. DW, SW and ZC provided scientific input and support with critical reading of the paper. SX and FC obtained the funding, critically revised the paper, and were fully responsible for the review conceiving and finalizing the paper. All authors read and approved the final version of the review paper.

\section{Compliance with ethical standards}

Conflict of interest The authors declare no competing interests.

Publisher's note Springer Nature remains neutral with regard to jurisdictional claims in published maps and institutional affiliations.

Open Access This article is licensed under a Creative Commons Attribution 4.0 International License, which permits use, sharing, adaptation, distribution and reproduction in any medium or format, as long as you give appropriate credit to the original author(s) and the source, provide a link to the Creative Commons license, and indicate if changes were made. The images or other third party material in this article are included in the article's Creative Commons license, unless indicated otherwise in a credit line to the material. If material is not included in the article's Creative Commons license and your intended use is not permitted by statutory regulation or exceeds the permitted use, you will need to obtain permission directly from the copyright holder. To view a copy of this license, visit http://creativecommons. org/licenses/by/4.0/.

\section{References}

1. Siegel RL, Miller KD, Jemal A. Cancer statistics, 2019. CA Cancer J Clin. 2019;69:7-34.

2. Bray F, Ferlay J, Soerjomataram I, Siegel RL, Torre LA, Jemal A. Global cancer statistics 2018: GLOBOCAN estimates of incidence and mortality worldwide for 36 cancers in 185 countries. CA Cancer J Clin. 2018;68:394-424.

3. Attard G, Parker C, Eeles RA, Schröder F, Tomlins SA, Tannock I, et al. Prostate cancer. Lancet (Lond, Engl). 2016;387:70-82.

4. Chandrasekar T, Yang JC, Gao AC, Evans CP. Mechanisms of resistance in castration-resistant prostate cancer (CRPC). Transl Androl Urol. 2015;4:365-80.
5. Reichert ZR, Hussain M. Androgen Receptor and Beyond, Targeting Androgen Signaling in Castration-Resistant Prostate Cancer. Cancer J. 2016;22:326-9.

6. Fontana F, Raimondi M, Marzagalli M, Di Domizio A, Limonta P. Natural Compounds in Prostate Cancer Prevention and Treatment: mechanisms of Action and Molecular Targets. Cells. 2020;9:460.

7. Stuchbery R, McCoy PJ, Hovens CM, Corcoran NM. Androgen synthesis in prostate cancer: do all roads lead to Rome? Nat Rev Urol. 2017;14:49-58.

8. Geller J, Albert JD, Nachtsheim DA, Loza D. Comparison of prostatic cancer tissue dihydrotestosterone levels at the time of relapse following orchiectomy or estrogen therapy. J Urol. 1984;132:693-6.

9. Barrie SE, Potter GA, Goddard PM, Haynes BP, Dowsett M, Jarman M. Pharmacology of novel steroidal inhibitors of cytochrome P450(17) alpha (17 alpha-hydroxylase/C17-20 lyase). J Steroid Biochem Mol Biol. 1994;50:267-73.

10. de Bono JS, Logothetis CJ, Molina A, Fizazi K, North S, Chu L, et al. Abiraterone and increased survival in metastatic prostate cancer. N Engl J Med. 2011;364:1995-2005.

11. Tran C, Ouk S, Clegg NJ, Chen Y, Watson PA, Arora V, et al. Development of a second-generation antiandrogen for treatment of advanced prostate cancer. Sci (N. Y, NY). 2009;324:787-90.

12. Scher HI, Fizazi K, Saad F, Taplin ME, Sternberg CN, Miller K, et al. Increased survival with enzalutamide in prostate cancer after chemotherapy. N Engl J Med. 2012;367:1187-97.

13. Mohler JL, Gregory CW, Ford OH 3rd, Kim D, Weaver CM, Petrusz $\mathrm{P}$, et al. The androgen axis in recurrent prostate cancer. Clin Cancer Res. 2004;10:440-8.

14. Titus MA, Schell MJ, Lih FB, Tomer KB, Mohler JL. Testosterone and dihydrotestosterone tissue levels in recurrent prostate cancer. Clin Cancer Res. 2005;11:4653-7.

15. Montgomery RB, Mostaghel EA, Vessella R, Hess DL, Kalhorn $\mathrm{TF}$, Higano CS, et al. Maintenance of intratumoral androgens in metastatic prostate cancer: a mechanism for castration-resistant tumor growth. Cancer Res. 2008;68:4447-54.

16. Cai C, Chen S, Ng P, Bubley GJ, Nelson PS, Mostaghel EA, et al. Intratumoral de novo steroid synthesis activates androgen receptor in castration-resistant prostate cancer and is upregulated by treatment with CYP17A1 inhibitors. Cancer Res. 2011;71: 6503-13.

17. Sharifi N. Minireview: androgen metabolism in castrationresistant prostate cancer. Mol Endocrinol. 2013;27:708-14.

18. Armandari I, Hamid AR, Verhaegh G, Schalken J. Intratumoral steroidogenesis in castration-resistant prostate cancer: a target for therapy. Prostate Int. 2014;2:105-13.

19. Penning TM. Androgen biosynthesis in castration-resistant prostate cancer. Endocr Relat Cancer. 2014;21:T67-78.

20. Grist E, de Bono JS, Attard G. Targeting extra-gonadal androgens in castration-resistant prostate cancer. J Steroid Biochem Mol Biol. 2015;145:157-63.

21. Grino PB, Griffin JE, Wilson JD. Testosterone at high concentrations interacts with the human androgen receptor similarly to dihydrotestosterone. Endocrinology. 1990;126:1165-72.

22. Wright AS, Douglas RC, Thomas LN, Lazier CB, Rittmaster RS. Androgen-induced regrowth in the castrated rat ventral prostate: role of 5alpha-reductase. Endocrinology. 1999;140:4509-15.

23. Xiao L, Wang Y, Xu K, Hu H, Xu Z, Wu D, et al. Nuclear receptor LRH-1 functions to promote castration-resistant growth of prostate cancer via its promotion of intratumoral androgen biosynthesis. Cancer Res. 2018;78:2205-18.

24. Wang Z, Wu D, Ng CF, Teoh JY, Yu S, Wang Y, et al. Nuclear receptor profiling in prostatospheroids and castration-resistant prostate cancer. Endocr Relat Cancer. 2018;25:35-50.

25. Locke JA, Guns ES, Lubik AA, Adomat HH, Hendy SC, Wood $\mathrm{CA}$, et al. Androgen levels increase by intratumoral de novo 
steroidogenesis during progression of castration-resistant prostate cancer. Cancer Res. 2008;68:6407-15.

26. Hofland J, van Weerden WM, Dits NF, Steenbergen J, van Leenders GJ, Jenster G, et al. Evidence of limited contributions for intratumoral steroidogenesis in prostate cancer. Cancer Res. 2010;70:1256-64.

27. Chang KH, Li R, Kuri B, Lotan Y, Roehrborn CG, Liu J, et al. A gain-of-function mutation in DHT synthesis in castration-resistant prostate cancer. Cell. 2013;154:1074-84.

28. Moore CC, Miller WL. The role of transcriptional regulation in steroid hormone biosynthesis. J Steroid Biochem Mol Biol. 1991;40:517-25.

29. Hum DW, Miller WL. Transcriptional regulation of human genes for steroidogenic enzymes. Clin Chem. 1993;39:333-40.

30. Evans RM. The nuclear receptor superfamily: a rosetta stone for physiology. Mol Endocrinol. 2005;19:1429-38.

31. Shi Y. Orphan nuclear receptors in drug discovery. Drug Discov Today. 2007;12:440-5.

32. Evans RM, Mangelsdorf DJ. Nuclear Receptors, RXR, and the Big Bang. Cell. 2014;157:255-66.

33. Baek SH, Kim KI. Emerging roles of orphan nuclear receptors in cancer. Annu Rev Physiol. 2014;76:177-95.

34. Zhao L, Zhou S, Gustafsson JA. Nuclear Receptors: recent Drug Discovery for Cancer Therapies. Endocr Rev. 2019;40:1207-49.

35. Wu D, Cheung A, Wang Y, Yu S, Chan FL. The emerging roles of orphan nuclear receptors in prostate cancer. Biochim Biophys Acta. 2016;1866:23-36.

36. Wang J, Zou JX, Xue X, Cai D, Zhang Y, Duan Z, et al. RORgamma drives androgen receptor expression and represents a therapeutic target in castration-resistant prostate cancer. Nat Med. 2016;22:488-96

37. Chen B, Yu S, Ding X, Jing C, Xia L, Wang M, et al. The role of testicular nuclear receptor 4 in chemo-resistance of docetaxel in castration-resistant prostate cancer. Cancer Gene Ther. 2014;21: $411-5$.

38. Jia L, Wu D, Wang Y, You W, Wang Z, Xiao L, et al. Orphan nuclear receptor TLX contributes to androgen insensitivity in castration-resistant prostate cancer via its repression of androgen receptor transcription. Oncogene. 2018;37:3340-55.

39. Xu Z, Wang Y, Xiao ZG, Zou C, Zhang X, Wang Z, et al. Nuclear receptor ERRalpha and transcription factor ERG form a reciprocal loop in the regulation of TMPRSS2:ERG fusion gene in prostate cancer. Oncogene. 2018;37:6259-74.

40. Xu Z, Ma T, Zhou J, Gao W, Li Y, Yu S, et al. Nuclear receptor ERRalpha contributes to castration-resistant growth of prostate cancer via its regulation of intratumoral androgen biosynthesis. Theranostics. 2020;10:4201-16.

41. Lewis SR, Hedman CJ, Ziegler T, Ricke WA, Jorgensen JS. Steroidogenic factor 1 promotes aggressive growth of castrationresistant prostate cancer cells by stimulating steroid synthesis and cell proliferation. Endocrinology. 2014;155:358-69.

42. Mathieu R, Evrard B, Fromont G, Rioux-Leclercq N, Godet J, Cathelineau X, et al. Expression screening of cancer/testis genes in prostate cancer identifies NR6A1 as a novel marker of disease progression and aggressiveness. Prostate. 2013;73:1103-14.

43. Li M, Xue K, Ling J, Diao FY, Cui YG, Liu JY. The orphan nuclear receptor NR4A1 regulates transcription of key steroidogenic enzymes in ovarian theca cells. Mol Cell Endocrinol. 2010;319:39-46.

44. Krylova IN, Sablin EP, Moore J, Xu RX, Waitt GM, MacKay JA, et al. Structural analyses reveal phosphatidyl inositols as ligands for the NR5 orphan receptors SF-1 and LRH-1. Cell. 2005; 120:343-55.

45. Fayard E, Auwerx J, Schoonjans K. LRH-1: an orphan nuclear receptor involved in development, metabolism and steroidogenesis. Trends Cell Biol. 2004;14:250-60.
46. Miki Y, Clyne CD, Suzuki T, Moriya T, Shibuya R, Nakamura Y, et al. Immunolocalization of liver receptor homologue-1 (LRH-1) in human breast carcinoma: possible regulator of insitu steroidogenesis. Cancer Lett. 2006;244:24-33.

47. Benod C, Vinogradova MV, Jouravel N, Kim GE, Fletterick RJ, Sablin EP. Nuclear receptor liver receptor homologue 1 (LRH-1) regulates pancreatic cancer cell growth and proliferation. Proc Natl Acad Sci USA. 2011;108:16927-31.

48. Wu C, Feng J, Li L, Wu Y, Xie H, Yin Y, et al. Liver receptor homologue 1 , a novel prognostic marker in colon cancer patients. Oncol Lett. 2018;16:2833-8.

49. Xiao L, Wang Y, Liang W, Liu L, Pan N, Deng H, et al. LRH-1 drives hepatocellular carcinoma partially through induction of cmyc and cyclin E1, and suppression of p21. Cancer Manag Res. 2018;10:2389-2400.

50. Chand AL, Pathirage N, Lazarus K, Chu S, Drummond AE, Fuller $\mathrm{PJ}$, et al. Liver receptor homologue-1 expression in ovarian epithelial and granulosa cell tumours. Steroids. 2013;78:700-6.

51. Clyne CD, Kovacic A, Speed CJ, Zhou J, Pezzi V, Simpson ER. Regulation of aromatase expression by the nuclear receptor LRH1 in adipose tissue. Mol Cell Endocrinol. 2004;215:39-44.

52. Sirianni R, Seely JB, Attia G, Stocco DM, Carr BR, Pezzi V, et al. Liver receptor homologue-1 is expressed in human steroidogenic tissues and activates transcription of genes encoding steroidogenic enzymes. J Endocrinol. 2002;174:R13-17.

53. Zhou J, Suzuki T, Kovacic A, Saito R, Miki Y, Ishida T, et al. Interactions between prostaglandin $\mathrm{E}(2)$, liver receptor homologue1, and aromatase in breast cancer. Cancer Res. 2005;65:657-63.

54. Meinsohn MC, Smith OE, Bertolin K, Murphy BD. The Orphan Nuclear Receptors Steroidogenic Factor-1 and Liver Receptor Homolog-1: structure, Regulation, and Essential Roles in Mammalian Reproduction. Physiol Rev. 2019;99:1249-79.

55. Parker KL, Rice DA, Lala DS, Ikeda Y, Luo X, Wong M, et al. Steroidogenic factor 1: an essential mediator of endocrine development. Recent Prog Horm Res. 2002;57:19-36.

56. Morohashi K, Honda S, Inomata Y, Handa H, Omura T. A common trans-acting factor, Ad4-binding protein, to the promoters of steroidogenic P-450s. J Biol Chem. 1992;267:17913-9.

57. Saxena D, Escamilla-Hernandez R, Little-Ihrig L, Zeleznik AJ. Liver receptor homolog-1 and steroidogenic factor-1 have similar actions on rat granulosa cell steroidogenesis. Endocrinology. 2007;148:726-34.

58. Ehrlund A, Jonsson P, Vedin LL, Williams C, Gustafsson J, Treuter E. Knockdown of SF-1 and RNF31 affects components of steroidogenesis, TGF $\beta$, and $\mathrm{Wnt} / \beta$-catenin signaling in adrenocortical carcinoma cells. PLoS ONE. 2012;7:e32080.

59. Miller S, Bhasin N, Urrego H, Moroz K, Rowan BG, Ramayya MS, et al. Genetic and epigenetic alterations of steroidogenic factor-1 in ovarian tumors. Int J Oncol. 2013;42:627-34.

60. Parakh TN, Hernandez JA, Grammer JC, Weck J, HunzickerDunn M, Zeleznik AJ, et al. Follicle-stimulating hormone/cAMP regulation of aromatase gene expression requires beta-catenin. Proc Natl Acad Sci USA. 2006;103:12435-40.

61. Del Tredici AL, Andersen CB, Currier EA, Ohrmund SR, Fairbain $\mathrm{LC}$, Lund $\mathrm{BW}$, et al. Identification of the first synthetic steroidogenic factor 1 inverse agonists: pharmacological modulation of steroidogenic enzymes. Mol Pharm. 2008;73:900-8.

62. Madoux F, Li X, Chase P, Zastrow G, Cameron MD, Conkright $\mathrm{JJ}$, et al. Potent, selective and cell penetrant inhibitors of SF-1 by functional ultra-high-throughput screening. Mol Pharm. 2008; 73:1776-84.

63. Eichner LJ, Giguere V. Estrogen related receptors (ERRs): a new dawn in transcriptional control of mitochondrial gene networks. Mitochondrion. 2011;11:544-52.

64. Fujimura T, Takahashi S, Urano T, Kumagai J, Ogushi T, HorieInoue $\mathrm{K}$, et al. Increased expression of estrogen-related receptor 
alpha (ERRalpha) is a negative prognostic predictor in human prostate cancer. Int J Cancer. 2007;120:2325-30.

65. Cheung CP, Yu S, Wong KB, Chan LW, Lai FM, Wang X, et al. Expression and functional study of estrogen receptor-related receptors in human prostatic cells and tissues. J Clin Endocrinol Metab. 2005;90:1830-44.

66. Zou C, Yu S, Xu Z, Wu D, Ng CF, Yao X, et al. ERRalpha augments HIF-1 signalling by directly interacting with HIF-1alpha in normoxic and hypoxic prostate cancer cells. J Pathol. 2014; 233:61-73.

67. Seely J, Amigh KS, Suzuki T, Mayhew B, Sasano H, Giguere V, et al. Transcriptional regulation of dehydroepiandrosterone sulfotransferase (SULT2A1) by estrogen-related receptor alpha. Endocrinology. 2005;146:3605-13.

68. Miao L, Shi J, Wang CY, Zhu Y, Du X, Jiao H, et al. Estrogen receptor-related receptor alpha mediates up-regulation of aromatase expression by prostaglandin E2 in prostate stromal cells. Mol Endocrinol. 2010;24:1175-86.

69. Milona A, Massafra V, Vos H, Naik J, Artigas N, Paterson HAB, et al. Steroidogenic control of liver metabolism through a nuclear receptor-network. Mol Metab. 2019;30:221-9.

70. Lin SC, Kao CY, Lee HJ, Creighton CJ, Ittmann MM, Tsai SJ, et al. Dysregulation of miRNAs-COUP-TFII-FOXM1-CENPF axis contributes to the metastasis of prostate cancer. Nat Commun. 2016; 7:11418.

71. Wang L, Xu M, Qin J, Lin SC, Lee HJ, Tsai SY, et al. MPC1, a key gene in cancer metabolism, is regulated by COUPTFII in human prostate cancer. Oncotarget. 2016;7:14673-83.

72. Qin J, Wu SP, Creighton CJ, Dai F, Xie X, Cheng CM, et al. COUP-TFII inhibits TGF-beta-induced growth barrier to promote prostate tumorigenesis. Nature. 2013;493:236-40.

73. Mendoza-Villarroel RE, Robert NM, Martin LJ, Brousseau C, Tremblay JJ. The nuclear receptor NR2F2 activates star expression and steroidogenesis in mouse MA-10 and MLTC-1 Leydig cells. Biol Reprod. 2014;91:26.
74. Buholzer CF, Arrighi JF, Abraham S, Piguet V, Capponi AM, Casal AJ. Chicken ovalbumin upstream promoter-transcription factor is a negative regulator of steroidogenesis in bovine adrenal glomerulosa cells. Mol Endocrinol. 2005;19:65-75.

75. Wu J, Sun H, Yang X, Sun X. Nur77 suppression facilitates androgen deprivation-induced cell invasion of prostate cancer cells mediated by TGF-beta signaling. Clin Transl Oncol. 2018; 20:1302-13.

76. Martin LJ, Tremblay JJ. The nuclear receptors NUR77 and SF1 play additive roles with c-JUN through distinct elements on the mouse Star promoter. J Mol Endocrinol. 2009;42:119-29.

77. Martin LJ, Boucher N, Brousseau C, Tremblay JJ. The orphan nuclear receptor NUR77 regulates hormone-induced StAR transcription in Leydig cells through cooperation with $\mathrm{Ca} 2+/$ calmodulin-dependent protein kinase I. Mol Endocrinol. 2008;22:2021-37.

78. Peng N, Kim JW, Rainey WE, Carr BR, Attia GR. The role of the orphan nuclear receptor, liver receptor homologue-1, in the regulation of human corpus luteum 3beta-hydroxysteroid dehydrogenase type II. J Clin Endocrinol Metab. 2003;88:6020-8.

79. Hanley NA, Rainey WE, Wilson DI, Ball SG, Parker KL. Expression profiles of SF-1, DAX1, and CYP17 in the human fetal adrenal gland: potential interactions in gene regulation. Mol Endocrinol. 2001;15:57-68.

80. Jimenez P, Saner K, Mayhew B, Rainey WE. GATA-6 is expressed in the human adrenal and regulates transcription of genes required for adrenal androgen biosynthesis. Endocrinology. 2003;144:4285-8.

81. Volle DH, Duggavathi R, Magnier BC, Houten SM, Cummins $\mathrm{CL}$, Lobaccaro JM, et al. The small heterodimer partner is a gonadal gatekeeper of sexual maturation in male mice. Genes Dev. 2007;21:303-15

82. Goodwin B, Jones SA, Price RR, Watson MA, McKee DD, Moore LB, et al. A regulatory cascade of the nuclear receptors FXR, SHP-1, and LRH-1 represses bile acid biosynthesis. Mol Cell. 2000;6:517-26. 